\title{
CONSTRUÇÃO DA INOVAÇÃO ENTRE AGRICULTORES E PESQUISADORES: OS GRUPOS DE AGRICULTORES EXPERIMENTADORES NO AGRESTE DA PARAIIBA.
}

\section{CONSTRUCTION OF INNOVATION AMONG FARMERS AND RESEARCHERS: THE FAR- MERS EXPERIMENTER GROUPS IN THE PARAÍBA, ARID ZONE (AGRESTE).}

\author{
Eric Sabourin ${ }^{1}$ \\ Pablo Sidersky ${ }^{2}$ \\ Luciano M. da Silveira ${ }^{3}$ \\ Henri Hocdé ${ }^{4}$
}

Resumo: O artigo analisa a evolução e os resultados das interações entre pesquisadores, técnicos e agricultores nos processos de apoio à inovação no caso de uma experiência no Agreste da Borborema, estado da Paraíba. O referencial da sociologia da inovação, os métodos de pesquisa-ação e de monitoramento foram mobilizados para acompanhar dispositivos de experimentação agropecuária em meio real, nos campos dos agricultores familiares. Os resultados empíricos desse acompanhamento trazem uma série de conhecimentos e referências sobre as relações de parceria local tecidas com vista a uma co-construção de inovações entre diversos tipos de atores. O trabalho examina, em particular, os métodos e dispositivos institucionais da interação entre pesquisadores e agricultores extensionistas, elaborados para assegurar diversas funções conjuntas e responder a objetivos compartilhados de pesquisa e de experimentação.

Palavras chave: Inovação Agropecuária, Parceria, Agricultores-Experimentadores, Paraíba-Brasil.

Abstract: The paper analyzes the evolution and the results of the interactions between researchers, technicians and farmers in the processes to support the innovation in the case of an experience in the arid zone of Borborema State of Paraiba. The Sociology framework of the innovation, the methods of action-research and monitoring were mobilized to monitor agricultural experimentation devices in real environment, in the fields of family farmers. The empirical results of this monitoring bring a lot of knowledge and references about the local partnership links woven with a view to co-construction of innovations between different types of actors. The paper examines, in particular, the methods and institutional devices of the interaction between researchers and extension farmers designed to ensure several joint functions or develop and respond to shared goals of research and experimentation.

Key words: Agricultural Innovation, Partnership, Peasant Experimentation, Paraiba-Brazil

\section{INTRODUÇÃO}

$\mathrm{O}$ artigo analisa a evolução e os resultados das interações entre agrônomos e agricultores em processos de apoio à inovação a partir de um caso no estado da Paraíba. A cooperação entre uma $\mathrm{ONG}$, sindicatos de trabalhadores rurais e pesquisadores da região do Agreste da Borborema tem dado lugar a um acompanhamento das relações de parceria para a co-construção de conhecimentos, referências e inovações.

Esta co-construção de inovação na região do Agreste foi iniciada pela atuação dos técnicos e agrônomos da Assessoria a Projetos e Agricultura Alternativa - AS-PTA, seguidos por pesquisadores do Centro de Cooperação Internacional em Pesquisa para o Desenvolvi-

1 CIRAD Umr Art-Dev, UnB-CDS

2 INCRA

3 AS-PTA

4 CIRAD, Umr Art-Dev 
mento -CIRAD e das universidades da região, em particular a Universidade Federal da Paraíba, Campi de Areias e de Campina Grande, que multiplicaram ações conjuntas com os agricultores, observando-os e aprendendo com eles.

Institucionalmente, esta abordagem passou pela multiplicação das relações e contatos dos agricultores familiares entre si e com agricultores familiares de outras regiões no Brasil e, inclusive, na América Central. O projeto levou também à implantação de uma experiência original em torno de grupos de agricultores experimentadores na escala da região do Agreste da Paraíba.

Como apoiar a inovação dos agricultores, quando essa já foi caracterizada como "discreta" (ALABALADEJO, 1999), "ordinária" (ALTER, 2000) ou até "invisível" (SABOURIN, 2009)?

Primeiramente, como descobrir a inovação endógena ou localizada? E, sobretudo, será que esta abordagem proporciona algum interesse e faz sentido para os agricultores e suas organizações? São estas as perguntas às quais tenta responder este artigo analisando um processo de mudança social e técnica na agricultura familiar do Agreste da Paraíba.

O referencial da sociologia da inovação e os métodos de pesquisa ação e de monitoramento foram mobilizados para acompanhar dispositivos de experimentação agropecuária em meio real durante dez anos, de 1996 a 2006, nos campos dos agricultores familiares. $\mathrm{O}$ acompanhamento social e sociológico da experiência associou observações regulares dos dispositivos de experimentação, participação nas diversas reuniões e visitas a campo, análise de arquivos (projetos, relatórios e atas de reuniões) e entrevistas abertas do conjunto dos atores envolvidos.

$\mathrm{O}$ artigo se divide em três partes $\mathrm{A}$ primeira trata do contexto do estudo de caso: apresenta o referencial teórico, o histórico das interações entre agrônomos e agricultores e os passos metodológicos do enfoque de construção da inovação. A segunda parte descreve o funcionamento dos grupos de agricultores experimentadores e a evolução do seu dispositivo técnico-institucional na escala do Agreste da Borborema. A terceira parte discute os resultados e apresenta os principais ensinamentos do caso.

\section{INTERAÇÕES ENTRE AGRICUL- TORES E AGRÔNOMOS}

\subsection{Referencial teórico e metodológico}

Os trabalhos conduzidos com os agricultores do Agreste da Paraíba se baseiam em duas constatações. Primeiro, a inovação segue um processo permanente de adaptação e não de simples criação-difusão. Para Schumpeter (1935), a inovação corresponde à elaboração de novas combinações entre diversos recursos (fatores de produção) e seu uso econômico e social. Para Flichy (1995), a dinâmica de inovação é o resultado de um processo de criatividade e aplicação de saberes. Segundo Gondard (1991), que retoma a distinção entre inovação e invenção estabelecida por Schumpeter, uma inovação é uma invenção que obteve sucesso ou que encontrou utilizadores.

Em segundo lugar, a inovação remete à área da ação coletiva. Darré (1986b) mostrou que os produtores inovam de forma individual na escala da parcela ou de sua unidade de produção, mas o fazem em função de interações entre si e com diversos atores e objetos no âmbito de redes e coletivos, tais como aqueles que foram analisados, entre outros, por Callon (1986; 1991).

Estas interações situam a inovação técnica em um conjunto mais amplo de inovações institucionais e de processos de aprendizagem em um contexto da ação coletiva que envolve as organizações de produtores, os serviços de apoio à agricultura, bem como as empresas de insumos e até a mídia (ALTER, 2000). No contexto da ação coletiva, a aprendizagem pode ser definida como uma produção e uma transformação de conhecimentos, dentro de uma perspectiva de coordenação entre atores (relações entre atores, normas e regras para a organização da ação...). De fato, para Hatchuel (2000), não é possível separar, nos processos de aprendizagem, os saberes das relações. Para Ostrom (1992), no centro da ação coletiva a aprendizagem é uma adap-

\begin{tabular}{|c|c|c|c|c|}
\hline Agric. Fam. & Belém-PA & n. 10 & p. 17-30 & dez. 2014 \\
\hline
\end{tabular}


tação conjunta dos saberes, normas e regras colocadas em prática.

As observações desta primeira parte resultam do monitoramento de um caso de produção coletiva de inovação na região do Agreste do estado da Paraíba desde 1995, entre a AS-PTA e agricultores vinculados aos sindicatos municipais de trabalhadores rurais. Esta parceria se construiu a partir da escolha de privilegiar e multiplicar as interações - aqui compreendidas como uma série organizada e programada de diálogos e ações recíprocas - entre pesquisadores e técnicos (agrônomos, zootécnicos, sem contar socioeconomistas e pedagogos) e grupos ou organizações locais de agricultores.

\subsection{Trajetória das interações entre técnicos, agricultores e pesquisadores.}

Os agricultores se organizaram em sindicatos na escala municipal e em associações de produtores na escala da comunidade camponesa. Na realidade, estas organizações não foram criadas para tratar das questões de produção agrícola. Seu primeiro objetivo consistia em garantir, para os sindicatos, o acesso aos serviços sociais e jurídicos ou, para as associações, o acesso às infraestruturas de base (escola, água, eletricidade...). Todavia, a colaboração entre a AS-PTA e os agricultores se construiu em torno da elaboração de alternativas técnicas. Mobilizada por uma demanda dos sindicatos dos municípios de Remígio, Solânea e Lagoa Seca, ela se estendeu progressivamente para associações comunitárias e de paróquia; e mais recentemente, para o Polo Sindical da Borborema, que agrupa as organizações de dezesseis municípios da região do entorno de Campina Grande.

Os primeiros contatos entre os sindicatos e a AS-PTA se deram durante ações de educação popular (formação sindical, alfabetização...) inspiradas nos métodos de análise da realidade propostos por Paulo Freire ${ }^{5}$. A prática de diagnóstico conjunto, dito "partici- pativo", foi a primeira ferramenta na base do diálogo entre técnicos e agricultores. Primeiro foi realizado um diagnóstico rápido dos sistemas agrários na escala municipal e, em seguida, foram aprofundados diversos temas (sistemas de pecuária, sementes, fertilidade, plantas locais, sistemas agroflorestais, exclusão social...) por meio de diagnósticos temáticos intermunicipais.

Durante os diagnósticos temáticos, foram identificadas práticas inovadoras de alguns agricultores que foram chamados de inovadores. Estas práticas experimentais espontâneas produziam resultados muitas vezes superiores àqueles dos testes de comportamento e ensaios multilocais implantados pela AS-PTA a partir de problemas identificados durante os diagnósticos. Por exemplo, as cercas de cactáceas e as barragens de pedra se revelavam mais adaptadas do que as faixas anti-erosivas ou as curvas nível; porque foram simplesmente apropriadas pelos agricultores. Da mesma maneira, eles consideraram o cultivo e o uso da melancia forrageira mais fácil do que a fabricação de ensilagem ou de feno. A associação milho-sorgo ou entre leguminosas (inclusive as arbóreas) intercaladas entre as fileiras de palma forrageira (Opuntia sp.) se mostrava mais produtiva do que a monocultura.

A identificação destes agricultores inovadores que, em geral, não pertenciam às organizações locais, levou os técnicos e sindicatos a conceber e testar dispositivos específicos para a experimentação. Dois tipos sucessivos de dispositivo de parceria foram implantados: primeiro, os grupos de interesse; e a partir de 1998, os grupos de Agricultores-Experimentadores (A-E) (SABOURIN et al., 2004b).

O grupo de interesse temático agrupava alguns agricultores, oriundos dos três municípios e envolvidos no mesmo tema; é um grupo animado por um técnico, voltado para a programação conjunta de estudos, visitas, experimentações e formações. De 1995 a 1998, nove grupos de interesse funcionaram acerca

5 Historiador e pedagogo brasileiro nascido em Recife (1921-1997), ele criou, durante os anos 60, um método de conscientização participante por meio de uma alfabetização que partia da realidade e dos problemas das classes populares. 
de problemas específicos: doença da bananeira, fertilização da batata, alimentação animal, fertilidade dos solos e sistemas agroflorestais. No início, eram constituídos por alguns agricultores que cuidavam ou acolhiam ensaios multilocais em suas parcelas. Com a participação de agricultores que operam diversos sistemas de produção, os grupos puderam integrar o funcionamento de toda a unidade de produção nas reflexões. Antes, isto era difícil, pois os diferentes grupos de interesse temáticos só socializavam seus resultados uma vez por ano. Como principal consequência, a diversidade das condições de produção passou a ser considerada. Isto levou a AS-PTA a investir em formas mais localizadas de organização do trabalho e de acompanhamento.

Os grupos de Agricultores-Experimentadores foram constituídos em 1997 a partir de agricultores voluntários, acompanhados pela AS-PTA. Assim os grupos de A-E utilizaram de forma sistemática as visitas de estudo e intercâmbio em torno das inovações e experimentações implantadas por centros de pesquisa ou por outros agricultores.

O acompanhamento é coletivo. As visitas a parcelas ou experiências são momentos e lugares privilegiados de trocas de informação entre A-E, agrônomos, pedagogos e demais agricultores interessados. A socialização final dos resultados é feita durante uma reunião de avaliação, no fim do ciclo agrícola ou do ano civil. A sistematização e valorização dos resultados e métodos sempre constituíram um ponto de estrangulamento e foram garantidas essencialmente pelos técnicos, às vezes por pesquisadores.

Ao longo dos anos, a lógica inicial se inverteu. Houve uma transição da participação dos camponeses às experimentações em meio real propostas pela AS-PTA, para um acompanhamento, pelos agrônomos, das experimentações individuais ou coletivas dos agricultores - As escolhas e projetos dos agricultores se tornaram determinantes, tanto do ponto de vista das temáticas quanto dos métodos; em particular, os critérios e indicadores de observação e, posteriormente, de avaliação.

\subsection{Um enfoque construtivista}

Aos poucos, o enfoque se consolidou em torno dos processos de aprendizagem e de um procedimento construtivista no sentido proposto por Piaget. Este processo pedagógico foi organizado em ciclos iterativos, segundo três fases:

a) A aprendizagem conjunta do outro e do meio.

Trata-se de compreender uma realidade e fazer com que cada um aprenda a conhecer o outro para que juntos possam atuar. $\mathrm{O}$ "conhecimento do outro" se torna conscientização mútua entre atores pertencentes a mundos e lógicas diferentes. Aprendizagem há, se houver (re)conhecimento, inclusive da especificidade e das estratégias do outro. Por exemplo: para os agrônomos: estratégias ligadas à necessidade de justificação dos financiamentos e resultados quantitativos; para os camponeses: necessidade de resultados concretos e adaptáveis aos seus sistemas diversificados. Às vezes, este reconhecimento mútuo foi construído em torno de objetos intermediários (no sentido proposto por VINCK, 1999) ou de representações comuns: os mapas e zoneamentos, as maquetes, as tipologias de unidades de produção, a representação dos Sistemas Locais de Conhecimento - SLC. Este (re) conhecimento constitui uma premissa e um motor para a ação conjunta.

b) Um plano para a ação: a experimentação e a divulgação.

A fase anterior permite definir regras para agir: a reciprocidade das dádivas de material vegetal durante visitas ou as normas de monitoramento dos ensaios. A programação corresponde a um processo de institucionalização: é o caso da construção de dispositivos coletivos ou de estruturas entre atores (grupos de interesse ou de A-E, redes de trocas, festas de A-E, jornadas por produtos,...); mas é também o caso da elaboração conjunta do protocolo de uma experimentação ou de uma lista de materiais necessários para sua implementação.

\begin{tabular}{|c|c|c|c|c|}
\hline Agric. Fam. & Belém-PA & n. 10 & p. 17-30 & dez. 2014 \\
\hline
\end{tabular}


Box 1: Princípios de ação da parceria (SABOURIN et al., 2006)

- dar aos agricultores e demais parceiros os meios de atuar, ao invés de atuar por si só: incentivar processos de mudanças/inovações ao invés da transferência de pacotes técnicos;

- estimular, de forma constante, interações entre agricultores, entre agricultores e pesquisadores, entre fazendeiros e camponeses sem-terra e entre situações contrastadas;

- formar e informar os agricultores sobre as políticas e métodos de pesquisa e extensão, para que possam compreender, criticar e interagir;

- garantir uma parceria a longo prazo e proporcionar, de forma concomitante, soluções de curto prazo, ainda que intermediárias, importadas, ou que remetam a modelos clássicos; - não se lançar em uma corrida que visa resultados imediatos, até mesmo sob pressão das instituições de financiamento;

- evitar a substituição e o isolamento: recorrer às instituições existentes, ainda que sejam imperfeitas, porém legítimas, ao invés de construir novas instituições.

c) A ação conjunta entre pares gerando saberes e valores.

Trabalhar juntos e produzir referências técnicas e ferramentas nas mesmas parcelas aproxima agrônomos e agricultores. A ajuda mútua e o compartilhamento dos saberes e da práxis constroem relações sociais e econômicas de reciprocidade que, por sua vez, produzem valores humanos éticos: respeito, amizade, confiança e principalmente responsabilidade e equidade. Participar da reprodução de tais valores sela alianças interindividuais e coletivas que contribuem para a parceria institucional.

Além da exigência da parceria, o esforço de aplicação do princípio de aprendizagem é essencial para este enfoque: fornecer os elementos-chave da percepção dos fenômenos, construir as soluções de forma coletiva e dizer não às receitas prontas. São princípios simples, mas exigentes para todos os atores envolvidos (Quadro 1).

Rapidamente, este procedimento, bastante original neste contexto e em torno de objetos técnicos e agrícolas, acarretou efeitos conjugados. Houve uma multiplicação dos agricultores que desejavam integrar processos de experimentação, atraídos pela dinâmica camponesa de generalização da reciprocidade. Notou-se que o principal objetivo do forte entusiasmo dos técnicos consistia em nutrir estes processos de experimentação, em detrimento de seu registro e da sistematização de seus resultados. Finalmente, obteve-se a colaboração de pesquisadores e universitários para garantir um apoio e um monitoramento científico mais rigoroso e contribuir com a valorização dos resultados.

Durante quase dez anos, esta dinâmica sócio profissional e sócio técnica complexa esteve sujeita a um acompanhamento pela pesquisa, realizado in situ (de 1998 até 2001) e por meio de visitas breves e pontuais (a partir de 2001) (SABOURIN et al., 2003, 2004b, 2006).

\section{OS GRUPOS DE AGRICULTORES-EX- PERIMENTADORES}

A partir de 1997, os grupos de agricultores inovadores, chamados de A-E, funcionaram de maneira informal, embora fossem reconhecidos no plano institucional, a partir do momento em que beneficiaram de um apoio técnico e financeiro de proximidade por parte da AS-PTA e das universidades.

\section{1-A parceria institucional com os agriculto- res inovadores}

Os grupos de A-E reúnem agricultores voluntários de uma mesma região que testam novas técnicas, práticas ou espécies em sua unidade de produção e aceitam de divulgar os métodos e resultados de suas experimentações.

O procedimento proposto não se insere na prática clássica de ensaios multilocais em meio camponês, que a pesquisa, os serviços 
de extensão ou as empresas de insumos costumam implantar. Situa-se no âmbito de uma co-concepção de inovações entre técnicos, pesquisadores e agricultores, fundamentada em processos de experimentação camponesa. Portanto, a experimentação corresponde a uma etapa metodológica em um processo de parceria negociada, marcado por escolhas comuns em termos de prioridades estratégicas e temas de inovação. A parceria institucional que determina o tipo de participação de cada instituição consiste, assim sendo, a conceber e explicitar o papel e o espaço de cada parceiro.

É possível fazer a distinção entre quatro funções da parceria institucional em torno dos A-E:

i) promover, animar e alimentar o funcionamento de grupos de A-E; ii) ajudar a sistematizar e avaliar os resultados (por meio de reuniões específicas); iii) socializar e difundir os resultados e as lições da experimentação camponesa; iv) alimentar alguns processos de experimentação em termos de métodos e material (material genético, referências, insumos, máquinas, etc.).
a)Programação e monitoramento de uma campanha de experimentação pelos agricultores.

No final do ano, as atividades dos grupos são programadas durante as reuniões de avaliação e programação, sendo em seguida assumidas conforme as necessidades de cada grupo. A partir daí, com o aumento do número de A-E, as associações comunitárias, bancos de sementes e sindicatos se encarregam de uma parte das tarefas (fornecimento de sementes, mudas, etc.). A AS-PTA assume, de forma provisória e por meio de fundos rotativos, novas necessidades, tais como financiamentos específicos para a implantação de determinados ensaios. Os diagnósticos participativos localizados ou temáticos (plantas locais, fertilidade, recursos hídricos,...) também constituem mecanismos importantes de auxílio na programação da experimentação. Como ilustração os quadros 1 e 2 apresentam exemplos de atividades dos grupos de A-E no caso do município de Solânea-PB, durante os anos 1998 a 2000.

Quadro 1: Atividades coletivas ligadas à experimentação no ano 2000, em Solânea-PB

\begin{tabular}{|c|c|c|c|c|c|c|c|}
\hline Comunidade & $\begin{array}{l}\text { Famílias } \\
\text { de A-E }\end{array}$ & $\begin{array}{l}\text { Famílias de } \\
\text { banco de } \\
\text { sementes }\end{array}$ & $\begin{array}{l}\text { Fundos rotativos } \\
\text { palma forrageira }\end{array}$ & $\begin{array}{c}\text { Fundos } \\
\text { rotativos } \\
\text { cisternas }\end{array}$ & Associações & $\begin{array}{c}\text { Caixas } \\
\text { de } \\
\text { crédito }\end{array}$ & $\begin{array}{l}\text { Grupos } \\
\text { Paróquia }\end{array}$ \\
\hline 1. Salgado de Souza & 8 & & 3 & & 1 & & \\
\hline \multicolumn{8}{|l|}{ 2. Corrimboque } \\
\hline 3. Palma & 5 & 13 & 3 & 1 & 1 & 1 & \\
\hline 4. Bomsucesso & 12 & 20 & 4 & 3 & 1 & & 1 \\
\hline 5. Goiana & 7 & 12 & 2 & 3 & 2 & 1 & \\
\hline 6. Fragoso & 2 & 17 & 2 & 1 & & & 1 \\
\hline 7. Pedra Grande & 6 & & & 1 & & 1 & 1 \\
\hline 8. Capivara & 1 & & & 1 & 1 & & \\
\hline 9. Açude Velho & - & & & 1 & & 1 & 1 \\
\hline 10. Várzea Cacimba & - & & & & 1 & & 1 \\
\hline 11. Varjota & - & & & 3 & & & \\
\hline 12. Tanque Preto & - & & & & 1 & & 1 \\
\hline
\end{tabular}

Fonte: Elaboração pelos autores 
Além do monitoramento individual dos ensaios específicos de cada A-E, é realizado um monitoramento coletivo que reúne os membros do grupo por meio de diversas atividades de reflexão e intercâmbio: visitas de estudo, excursões, visitas de ensaios camponeses, reuniões de programação ou avaliação. A socialização final dos resultados e referências produzidos é realizada durante uma reunião de avaliação, ao final do ciclo agríco- la ou do ano civil. Esta socialização também pode ocorrer por ocasião de uma jornada de demonstração, um dia de campo, um curso de formação ou mesmo uma festa local ou municipal, como aquelas que são organizadas a cada ano pelos sindicatos municipais e pelos grupos de agricultores (Quadro 2).

Quadro 2: Temas de experimentação do grupo de A-E da microrregião do Curimataú (Solânea-PB) no período 1998-2000

\begin{tabular}{|c|c|c|c|}
\hline Temas de experimentação & Origem & Comunidades & Número de A-E \\
\hline \multicolumn{4}{|l|}{ Luta contra a erosão } \\
\hline 1- micro-barragens de pedras & espontânea e local & 2 & 3 \\
\hline 2- faixas de vetiver em curva de nível & AS-PTA Sul do Brasil & 2 & 6 \\
\hline 3- cercas vivas de cactáceas, bromeliáceas e plantas locais & espontânea e local & 6 & 15 \\
\hline 4- aleias de cajanus cajan e gliricidia & diversas & 2 & 4 \\
\hline \multicolumn{4}{|l|}{ Intensificação forrageira } \\
\hline \multicolumn{4}{|l|}{ Produção de biomassa } \\
\hline 5- campo de milho ou de sorgo puro & AS-PTA & 6 & 18 \\
\hline 6- sorgo e cajanus cajan consorciados com cultivos anuais & espontânea e local & 5 & 10 \\
\hline 7- plantações de aleias forrageiras & diversas & 3 & 5 \\
\hline 8- plantação de forrageiras arbóreas nas cercas vivas & espontânea e local & 4 & 15 \\
\hline 9- valorização de baixios & espontânea e local & 4 & 5 \\
\hline 10- plantação de melancia forrageira & espontânea e local & 6 & 20 \\
\hline 11- plantação de palma forrageira consorciada & espontânea e local & 6 & 16 \\
\hline 12- pracinhas de pastos & EMBRAPA & 8 & 4 \\
\hline \multicolumn{4}{|l|}{ Conservação de forragens } \\
\hline 13-fenil & Diversas, Embrapa & 6 & 14 \\
\hline 14- ensilagem (4 tipos de silo) & AS-PTA, EMATER & 6 & 18 \\
\hline \multicolumn{4}{|l|}{ Diversificação } \\
\hline 15- introdução de plantas medicinais & Paróquia & 3 & 9 \\
\hline 16- introdução de amendoim e gergelim & EMBRAPA & 6 & 11 \\
\hline 17- variedades de feijão & espontânea & 3 & 5 \\
\hline 18. viveiros de árvores (frutíferas, madeira e leguminosas) & AS-PTA & 3 & 3 \\
\hline 19- introdução de pecuária ovina & espontânea, EMATER & 2 & 3 \\
\hline \multicolumn{4}{|l|}{ Fertilidade } \\
\hline 20- uso do estrume & diversas & 2 & 4 \\
\hline 21- uso de resíduos de sisal & espontânea e local & 2 & 2 \\
\hline 22- pequenos bosques, pousios arbóreos de longo prazo & espontânea e local & 2 & 6 \\
\hline \multicolumn{4}{|l|}{ Manejo da água } \\
\hline 23- barragens & fazendeiros & 2 & 6 \\
\hline 24- cisternas & AS-PTA & 8 & 25 \\
\hline
\end{tabular}

Siglas: AS-PTA: Assessoria Serviços a Projetos de Agricultura Alternativa, EMATER: Empresa de Assistência Técnica e extensão Rural; EMBRAPA: Empresa Brasileira de Pesquisa Agropecuária; UFPB: Universidade Federal da Paraíba.

Fonte: Elaboração pelos autores 
Figura 1: Evolução das ferramentas e dispositivos coletivos de inovação no Agreste

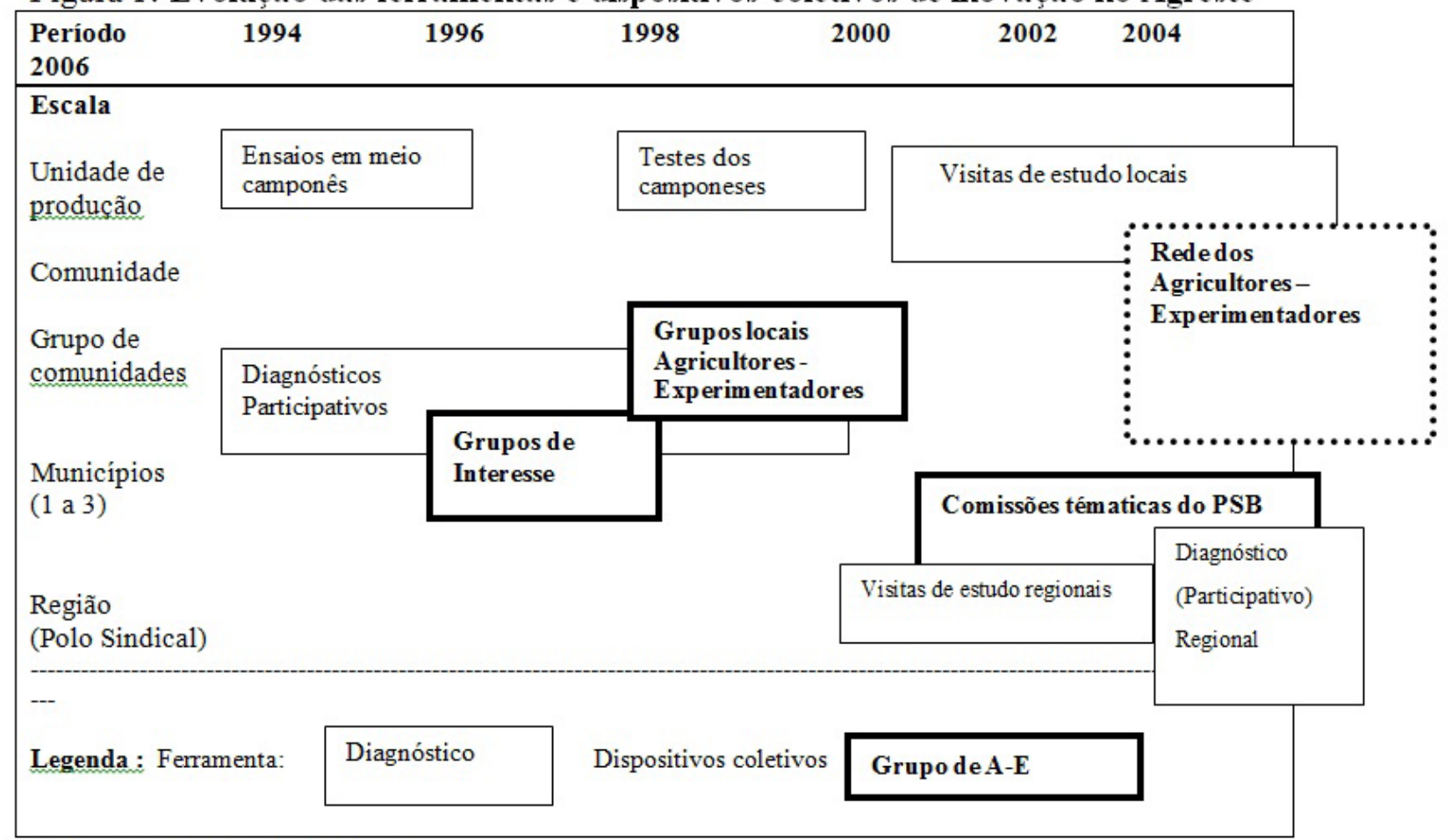

Fonte: Elaboração pelos autores

A evolução dos comportamentos dos agricultores no âmbito dos grupos de A-E, entre fases de ação individual e coletiva, confirma a alternância identificada por Aggeri (2002), entre momentos de segregação e de socialização. Conceber a inovação é antes de tudo a questão de um ou alguns indivíduos envolvidos e motivados; em contrapartida, adaptá-la ou validá-la posteriormente depende de mecanismos de socialização e co-prescrição por outros atores já que, como bem mostrou Darré (1996), os inovadores se encontram fora das normas, ou até mesmo são considerados como desviantes das normas locais.

\subsection{Evolução dos dispositivos coletivos}

De 1997 a 2000, o número de experimentadores dos três municípios passou de 50 a 200; cada um realizava vários ensaios por ano.

O método de monitoramento/acompanhamento testado entre 1997 e 2000 revelou consumir muitíssimo tempo para a equipe da AS-PTA. A partir de 2002, diante do boom de iniciativas e demandas decorrente da ampliação para os dezesseis municípios que constituem o território da Borborema, a AS-PTA modificou seu sistema de acompanhamento e favoreceu a autonomia dos grupos de A-E. O apoio passou a ser metodológico e logístico, por meio de sessões de formação, de um lado, e de fornecimento de material vegetal e insumos, de outro. Os animadores dos sindicatos e os primeiros A-E se encarregaram da intermediação, assumindo uma função de monitores junto aos agricultores dos novos municípios do polo da Borborema (Figura 1).

A mudança de escala operada a partir de 2002 acarretou dificuldades de sistematização e valorização dos resultados. Por isso, a função de formação ficou reduzida; somente aqueles agricultores que estavam mais bem preparados se beneficiaram com as referências e informações mais sofisticadas. As ações coletivas foram programadas conforme quatro comissões temáticas de escala regional: água,

6 Referência: informação que abrange a caracterização da prática e do contexto no qual é implementada, bem como os resultados alcançados.

\begin{tabular}{|c|c|c|c|c|}
\hline Agric. Fam. & Belém-PA & n. 10 & p. 17-30 & dez. 2014 \\
\hline
\end{tabular}


sementes, pecuária, alimentação e saúde.

A institucionalização dos grupos de A-E, por meio de dispositivos coletivos autônomos ou no âmbito das associações e sindicatos, é uma hipótese de perenização formulada no início do processo, que não foi verificada. Em contrapartida, nos municípios iniciais, a atividade de experimentação foi mantida, bem como os laços entre os núcleos de indivíduos ativos que estão na base de cada grupo de A-E.

No plano regional do Polo sindical da Borborema, este dispositivo, que tem por base as comissões temáticas, as visitas de intercâmbio e as atividades de monitores dos A-E parece favorecer uma institucionalização mínima, sob forma de uma rede de A-E. Mas se trata de uma rede de elite e não mais de vizinhos que se passam convites ou realizam trocas mútuas em função da proximidade social e geográfica. Segundo os camponeses, esta institucionalização arrisca não trazer nada além de burocracia.

Assim, de certa forma, em escala local, passamos da democracia direta para a delegação da autoridade que se constitui como poder e não mais tem por base a democracia e reciprocidade e sim a organização da produção visando objetivos materiais e as complementaridades seletivas; nasce então a burocracia... Além das ações em massa, apoiadas pelos poderes públicos (bancos de conservação e distribuição de sementes e mudas, cisternas de coleta de águas de chuva), as atuações não alcançam facilmente as famílias mais pobres ou isoladas do ponto de vista institucional ou geográfico.

\section{ENSINAMENTOS EM TERMOS DE APOIO AOS PROCESSOS DE INOVAÇÃO}

Os agricultores procuram melhorar a eficácia de seus sistemas de produção (desempenhos e condições de trabalho), adotando diversas propostas locais e externas. Assim, os agricultores produzem referências locais ${ }^{6}$.

Podem também contribuir para a socialização de informações, por meio dos mecanismos sociais de proximidade e das redes de relações interpessoais. $\mathrm{Na}$ verdade, eles implantam o quadro organizacional (dispositivos, regras, formas de coordenação) que faz com que os artefatos técnicos (sementes, associações de culturas, barragens...) possam se tornar elementos de inovação nos sistemas locais de produção. Mas faz-se necessário este diálogo entre agricultores e instituições, ainda que se dê por meio dos sindicatos ou da AS-PTA, para que os dispositivos estabilizados de experimentação possam funcionar; dispositivos que, afinal, tornam possível a coprodução de referências entre técnicos e comunidades. Mais do que os próprios grupos de A-E diretamente, são os sindicatos ou foros regionais híbridos que continuam assumindo o papel de tradutor ou porta-voz de lógicas diferenciadas de inovações (no sentido proposto por AKRICH et al., 1988) junto às instituições públicas.

Em contrapartida, os agricultores desenvolvem capacidades de aprendizagem. Os conhecimentos científicos sobre ecologia, biologia, economia e filosofia, sempre que estejam acessíveis, são incorporados aos processos de inovação. Por exemplo, as informações sobre a ecologia dos insetos foram valorizadas para lutar contra a propagação do verme da bananeira; os dados sobre a umidade do ar foram integrados para melhorar a secagem dos grãos. No plano comunitário, os agricultores implantaram práticas específicas de ajuda mútua e organização que levam à atualização de processos antigos de reciprocidade camponesa. Assim, mesmo partindo de apoios externos, foram capazes de adaptar modelos institucionais (BARBIER; LEMERY, 2000).

\subsection{O papel das organizações profissio- nais}

Há várias formas de coordenação, grupos e estruturas destinadas a cuidar de funções múltiplas em torno da produção agrícola e da vida das comunidades camponesas. Pode-se distinguir entre as estruturas criadas de forma específica para a inovação técnica (bancos de sementes, grupos de interesse, grupos de A-E,...) e as organizações generalistas (associações, sindicatos, cooperativas,...).

A questão da parceria para construção 
de inovação entre as estruturas camponesas, as organizações profissionais agrícolas e os poderes públicos pressupõe que os grupos de experimentação sejam, minimamente, institucionalizados. Esta parceria pode passar pelas estruturas existentes ou pela criação de novas organizações.

As estruturas especializadas são mais propícias ao desenvolvimento de processos de inovação; mas em geral elas funcionam por meio de redes limitadas ou seletivas e podem trazer os mesmos problemas de assimetria de informação, ou até mesmo de exclusão, que as atuações das instituições públicas. Este é o motivo pelo qual o modelo de grupo de A-E que funciona no âmbito de organizações generalistas oferece mais garantia de socialização dos resultados. As referências latino-americanas, na Argentina (CHIA; DEDIEU, 2002) ou na América Central (HOCDÉ, 1997; 1999), foram aproveitadas, levando em conta a proximidade do contexto; mas uma reflexão específica se desenvolveu no plano do sindicalismo camponês brasileiro em torno da abordagem territorial da inovação. Hoje, ela é assumida pelo grupo de trabalho sobre construção do conhecimento agroecológico, no âmbito da Associação Nacional de Agroecologia (ANA-GT info) e da Associação Brasileira de Agroecologia - ABA (Petersen, 2006).

É mesmo em termos de ambiente institucional e atitudes de serviços públicos de Pesquisa \& Desenvolvimento (P\&D) que a maioria das dúvidas reside quanto à implantação deste tipo de parceria. Os pesquisadores e técnicos não foram formados para trabalhar a partir da valorização do saber e do saber fazer dos agricultores.

\subsection{As dificuldades e os limites da institu- cionalização}

$\mathrm{O}$ apoio institucional a grupos de A-E pode constituir uma interface entre o nível da ação individual e o da ação pública que proporcione alternativas para os serviços de extensão agrícola. Este tipo de método representa um avanço em relação a dispositivos descendentes (extensão rural clássica, training and visit,...) ou a sistemas bastante rí- gidos ou exigentes em termos de registro de dados, tais como as redes de fazendas de referência. Mas o apoio dado aos grupos de A-E se mostra muito exigente também em termos de recursos humanos. Entre 1998 e 2000, o monitoramento de seis grupos de A-E mobilizou, em média, três técnicos e pesquisadores e três diretores dos sindicatos ao longo do ano; algo que, nada supérfluo, constitui uma taxa bem superior às normas da assistência técnica e extensão pública. Por fim, não se trata de substituir as funções da pesquisa e da extensão, embora aquelas sejam falhas, pela ação dos agricultores. Pelo contrário, por natureza, uma dinâmica regional de experimentação camponesa leva rapidamente a solicitações crescentes dos centros de P\&D. Não é possível conceber que um apoio seja prestado aos grupos de A-E sem que reformas sejam feitas no âmbito das instituições de P\&D. É até questão de transformar uma dinâmica exploratória de construção de parcerias (AGGERI, 2002; LINDENPERG, 1999) em colaborações institucionais flexíveis e pontuais no que tange aos dispositivos de inovação e construção de objetos de pesquisa.

Para as instituições públicas envolvidas no enfoque e que nele desejem se inspirar para renovar os métodos de extensão agrícola, a principal restrição é o nível de recursos necessários do ponto de vista humano, técnico e financeiro. $\mathrm{O}$ governo brasileiro empreendeu a partir de 2003 uma reforma do sistema de extensão. Alguns responsáveis do programa de Crédito Fundiário do Ministério do Desenvolvimento Agrário - MDA propuseram uma generalização dos grupos de A-E, pelo menos para apoiar os agricultores da Paraíba atendidos pelo programa. Estes atuariam tanto como monitores quanto como técnicos, formando seus próprios corpos técnicos; organizar-se-iam em cooperativas ou no âmbito das associações de agricultores existentes. Mesmo com apoios consistentes, adotar este rumo ainda não funcionou na Borborema. Mesmo se o Estado dispusesse dos recursos institucionais e financeiros, o empreendimento continuaria incerto. $\mathrm{O}$ processo analisado no Agreste da Paraíba se construiu de forma social e institucional durante mais de dez anos, entre ato-

\begin{tabular}{|l|l|l|l|l|}
\hline Agric. Fam. & Belém-PA & n. 10 & p. 17-30 & dez. 2014 \\
\hline
\end{tabular}


res e personalidades que se identificaram, que se reconheceram e optaram por trabalharem juntos. Porém, no caso do programa de Crédito Fundiário, o prazo para constituir equipes ou instituições de assistência técnica paga é de apenas dois anos, o que torna praticamente impossível montar um grupo ou uma rede de A-E. Aliás, a ideologia penetra também os argumentos em favor das abordagens participativas; pois na verdade, tanto o Banco Mundial quanto o Banco Interamericano de Desenvolvimento (BID) pretendem apoiar, antes de tudo, a privatização dos serviços de extensão, no âmbito dos programas de reforma agrária pelo mercado. Em contrapartida, é possível lançar o procedimento contrário, ou seja, o reconhecimento pelo Estado das experiências de A-E ou de assistência técnica assumida pelas organizações de agricultores, que já estão em andamento na Paraíba e no resto do Brasil e, logo, o apoio à sua institucionalização e funcionamento. O Polo Sindical da Borborema solicitou que estes grupos de A-E sejam integrados, em sua região, ao processo de desenvolvimento territorial apoiado pelo MDA, mas não conseguiu até hoje mobilizar recursos específicos. Os fundos do Programa Nacional de Desenvolvimento Territorial-PDSTR são reservados apenas a infraestruturas e equipamentos, via entidades estaduais ou municipais.

De fato, estes dispositivos coletivos entre agricultores, sindicatos e demais instituições, marcados pela espontaneidade e o voluntarismo, carecem, muitas vezes, de práticas contratuais ou até mesmo de regras sistematizadas e sancionadas. Diversidade, autonomia e criatividade foram estimuladas por esta flexibilidade que acarretou também, por vezes, anomia e fragilidade. É, por exemplo, o caso para o registro e a socialização dos resultados dos ensaios, ou o reembolso dos créditos para as parcelas de palma forrageira. A fraqueza das regras no âmbito destes dispositivos pode restringir a produção, a socialização e a apropriação de resultados.

As dificuldades de diálogo e reconhecimento dos outros não se atêm apenas aos grupos de agricultores; parte da responsabilidade é dos pesquisadores.
Exemplo disto é a pesquisa sobre a fertilidade e fluxos de biomassa no Agreste da Paraíba (TONNEAU et al., 2002). A colaboração dos universitários, justificada pela necessidade de validação científica dos resultados da experimentação camponesa, foi difícil. Os pesquisadores não apresentavam o envolvimento, a experiência e o domínio das ferramentas participativas adquiridas pelos técnicos da AS-PTA. Faltou a fase inicial de formação dos agricultores sobre a concepção da pesquisa e o domínio das ferramentas. Os trabalhos delegados a equipes universitárias foram realizados por estagiários, aceitos pelos camponeses mais na base da amizade que da competência. Os dispositivos foram mal dimensionados; muitas vezes, a coleta dos dados foi ruim (pois camponeses e estudantes não compreendiam sua razão de ser) ou incompleta.

A experiência mostra a dificuldade de se manter a co-construção de métodos, saberes e inovações. Esta dificuldade ocorreu também no âmbito dos grupos de A-E. Na falta de um dispositivo de monitoramento e avaliação institucionalizado ou contratual, os agricultores não registram resultados ou se lembram apenas dos seus próprios critérios e indicadores de avaliação: resistência, rusticidade, comportamento ao longo do ciclo, retorno forrageiro das palhas e restos de culturas. Estes critérios são relevantes, mas devem ser associados a indicadores mensuráveis, sempre que o objetivo seja convencer a pesquisa agronômica do interesse das práticas camponesas ou agroecológicas ou produzir referências para a região.

As experimentações que estiveram sujeitas a algum tipo de monitoramento dos centros de pesquisa foram aquelas que diziam respeito às mensurações e análises de fluxo de biomassa. Estas análises contribuíram para verificar os resultados das práticas agroecológicas (culturas associadas, adubo verde e orgânico, aleias de leguminosas, sistemas agroflorestais,...), em termos de rendimentos e comportamento da fertilidade dos solos.

Em 2006, atendendo uma demanda de comercialização de algodão orgânico, o centro EMBRAPA Algodão tomou contato com um grupo de A-E para que estes se encarreguem 
de experimentar a conversão das variedades regionais no sistema de cultura agroecológico.

Estas evoluções mostram que fora um desejo de serem apoiados e acompanhados pelos centros de pesquisa e desenvolvimento, os A-E só se encarregam das funções de experimentação quando existe uma compensação ou motivação prática ou econômica como as perspectivas do algodão orgânico.

\section{CONCLUSÃO}

A análise da trajetória dos grupos de agricultores-experimentadores no Agreste da Borborema traz uma série de elementos novos por conta do acompanhamento do dispositivo durante quase dez anos e pela extensão progressiva do mesmo de 2 a 4, 5 e finalmente 15 municípios no marco do Polo Sindical e logo do território da Borborema

Concretamente, na rede de A-E dos 16 municípios do território da Borborema, as dinâmicas de experimentação coletiva e de produção e socialização de referências têm funcionado com grande capilaridade e atingindo até produtores tradicionalmente marginalizados, quando foram associadas a programas de apoio (governamentais ou não).

Em termos de manejo da água, a difusão foi relativamente ampla porque a experimentação estava ligada primeiro ao programa de construção de cisternas (P1MC), do qual o Polo Sindical da Borborema constitui uma das unidades gestoras na região e, segundo ao Programa "1 terra 2 águas", promovido pela Articulação do Semiárido, a ASA Brasil.

Em segundo lugar, houve uma dinâmica de fortalecimento da experimentação e da produção agroecológica por meio da implantação das feiras agroecológicas em vários municípios pelo PSB, que ensejou reuniões e intercâmbios técnicos entre produtores de frutas e legumes, mel e, em menor proporção, aves e queijo. Em 2005, as associações de produtores das feiras agroecológicas da Borborema organizaram um encontro na escala do estado da Paraíba, com os produtores das feiras do Alto Sertão e litoral. Em 2006, os mesmos fundaram uma articulação dos produtores dos mercados agroecológicos que organizou o primeiro encontro de agricultores experimentadores da Paraíba.

Os ensinamentos metodológicos são diversos e importantes.

Primeiro, o dispositivo da Borborema permitiu identificar, qualificar e difundir múltiplos casos de inovação local ou endógena, trabalhados e socializados por agricultores familiares, e que passaram a constituir referencias regionais.

Segundo, ajudou a testar e validar métodos que mobilizam no mínimo o interesse e a participação dos agricultores e até investimentos duradouros das suas organizações.

Em terceiro lugar, o trabalho de monitoramento mostra como a validade e a reprodutibilidade deste tipo de experiência depende amplamente das capacidades de capitalização, valorização e de divulgação dos resultados pelas organizações de agricultores como pelos centros de P\&D. Do ponto de vista institucional essas dinâmicas estão ligadas a diversas formas de reconhecimento, de apoio ao funcionamento ou a perenidade dos dispositivos coletivos dos agricultores e as suas capacidades de articulação contratual com os serviços de pesquisa e extensão, sejam privados ou públicos.

Em quarto lugar, dialogar no respeito mútuo entre agricultores, extensionistas e pesquisadores pressupõe respeitar, conhecer o outro e levar em conta suas necessidades específicas. O tempo passado em relacionamentos humanos para o diálogo, a formação, o diagnóstico conjunto, o monitoramento-avaliação, a restituição dos resultados tem sido determinante e exigente em recursos humanos. Essa abordagem passa por um processo de formação contínua dos agrônomos, bem como dos agricultores. Tais condições, por si só, indicam também os limites da experiência.

Estas interações com os agricultores e com outros atores colocam em posição-chave os técnicos e pesquisadores dotados de uma capacidade de resposta em termos de métodos e monitoramento dos processos de inovação mais do que de transferência imediata de tecnologias. Melhor seria, ainda, se estes pesquisadores e extensionistas fossem acompanhados por suas instituições. Diante do de-

\begin{tabular}{|c|c|c|c|c|}
\hline Agric. Fam. & Belém-PA & n. 10 & p. 17-30 & dez. 2014 \\
\hline
\end{tabular}


safio e da dificuldade da mudança de escala, um dos resultados da experiência do apoio aos A-E da Borborema consistiu em fornecer meios e competências para que organizações de agricultores possam negociar diretamente um reconhecimento e uma assistência mais adaptada junto aos serviços de pesquisa e desenvolvimento.

\section{REFERÊNCIAS}

AGGERI F. La construction des objets de la recherche dans les partenariats d'exploration. In: Recherches pour et sur le développement régional, DADP. Montpellier: Inra, 2002, p. 71-89.

\section{AKRICH, M; CALLON, M; LATOUR, B. À} quoi tient le succès des innovations. Deuxième épisode: 1 'art de choisir les bons porte-parole. Annales des Mines, gérer et comprendre; 1988, p.14-29.

ALBALADEJO, C. Réflexions sur la notion de systèmes locaux de connaissance à partir de projets de recherche/formation et développement en Amérique Latine. In: COLLOQUE REFERENCES TECHNICO-ECONOMIQUES, 1999. Actes... Montpellier: Cirad, 1999, p.137-154.

ALTER N. L'innovation ordinaire. Paris: PUF, 2000. 278p

AS-PTA, Agricultores familiares do Agreste Paraibano: o caso dos municípios de Solânea e Remígio. Solânea-PB: AS-PTA, 1997. 28p.

BARBIER M; LEMERY B. Learning through processes of Change in Agriculture: a methodological framework. In: Cow up a tree: knowing and learning for change in agriculture. case studies from industrialised countries. Learn group (eds). Paris: INRA, 2000, p. 381-393

CALLON, M. Eléments pour une sociologie de la traduction: la domestication des coquil- les Saint-Jacques et des marins pêcheurs dans la baie de Saint-Brieuc. L'Année Sociologique. n. 36, p.169-208, 1986,

CALLON, M. Réseaux technico-économiques et irréversibilités. In: BOYER, B; CHAVANCE, B;. GODARD, O.(ed). Les figures de l'irréversibilité en économie. Paris: EHESS, 1991, p.195-232

CHIA E; DEDIEU, B. Nouveaux dispositifs de $\mathrm{RD}$ en agriculture : le programme franco-argentin IDEAS. Cahiers Agricultures. n. 11, p. 259-267, 2002.

DARRE J.P. La production de connaissances dans les groupes locaux des agriculteurs, Agriscope. n. 7, p.24-35, , 1986.

DARRE, J.P. Comment les façons de faire et de penser se transforment: l'étude des réseaux de dialogue, Agriscope. n7, p.143-151, 1986.

DARRE, J.P. L'invention des pratiques dans l'agriculture: vulgarisation et production locale de connaissance. Paris: Karthala/CNRS, 1996, p.200.

FLICHY, P. L'innovation technique: récents développements en sciences sociales. Vers une nouvelle théorie de l'innovation. Paris : la Découverte, 1995. 251p

FREIRE P. Educação e conscientização: extencionismo rural. Cuernavaca, México, CIDOC, 1968. 320 p. (Cuaderno 25)

FREIRE P. Alfabetização e conscientização. Porto Alegre : Editora Emma, 1963

GONDARD P. L'innovation agraire en PVD : concept et méthodes d'observation. In:

L'innovation en milieu rural, doc LEA 1. Montpellier : Orstom, 1991, p. 5-11

HATCHUEL, A. Apprentissages collectifs et activités de conception. Revue Française de gestion. Juin-aout, p 109-120, 1994. 
HATCHUEL, A. Quel horizon pour les sciences de gestion? Vers une théorie de l'action collective. In: DAVID, A.; HATCHUEL, R.; LAUFER. Les nouvelles fondations des sciences de gestion. Paris : Vuibert FNEGE, 2000, p.7-43.

HOCDE, H. No quiero plata, quiero conocimientos, no equivocarse de planteamiento! San José, Costa Rica: IICA-PRIAG, 1997, p55. (série estratégica, Documento 22)

HOCDE, H. A lógica dos agricultores-experimentadores: o caso da América Central. Rio de Janeiro AS-PTA, 1999. 36p. (Série metodologias participativas, 2)

LINDENPERG, G. Les acteurs de la formation professionnelle: pour une nouvelle donne. Paris: Rapport au Premier Ministre, 1999. 135p.

OSTROM, E. Crafting Institutions for self-governing irrigation systems. San Francisco: ICS Pres, Institute for Contemporary Studies, 1992. 228p.

PETERSEN, P. Agroecologia em rede: fonte de inspirações para a inovação local. Agriculturas, experiências em agroecologia. v. 3, n 2, p. 30-33, 2006.

SABOURIN, E et al. Gestion technique vs gestion sociale de l'eau dans les systèmes d'agriculture familiale du Sertão brésilien. Sècheresse. v.13, n. 4, p.274-83, 2002.

SABOURIN, E; SILVEIRA, L; SIDERSKY, P. Production d'innovation en partenariat et agriculteurs expérimentateurs au Nordeste du Brésil. Cahiers Agricultures. v.13, p. 203210, 2004.

SABOURIN, E; SIDERSKY, P; SILVEIRA L. Farmer experimentation in northeast Brazil: The story of a partnership between smallholders' organisations and an NGO seeking to enhance agricultural innovation in the Agreste region of Paraíba State. In: Advancing Participatory Technology Development. La
Haye: ACP-EU,CTA, 2004, p.191-207 SABOURIN E, HOCDE H, TONNEAU JP, SIDERSKY. P Production d'innovations et interactions agronomes/agriculteurs dans l'Agreste de la Paraíba, Brésil. In: CANEILL, Jacques. Agronomes et Innovations : 3ème édition des entretiens du Pradel. Paris:

L'Harmattan. 2006

SCHUMPETER J.A. La théorie de l'évolution économique. Paris: DALLOZ, 1935. 586p

SIDERSKY P; SILVEIRA L. Experimentar com os agricultores: a experiência da AS-PTA na Paraiba. In: Metodologias de experimentação com os agricultores, Embrapa, Brasília G Filho (ed). 2000, p33-58. (Serie Agricultura Familiar, 5).

TONNEAU, JP. et al. Modélisation des flux de biomasse: une approche de la fertilité dans l'Agreste de la Paraíba. Cahiers Agricultures, n.11, p.127-136, 2002.

VINCK, D., Les objets intermédiaires dans les réseaux de coopération scientifique. Contribution à la prise en compte des objets dans les dynamiques sociales. Revue française de sociologie, v.40, n.2, p385-414, 1999.

\begin{tabular}{|c|c|c|c|c|}
\hline Agric. Fam. & Belém-PA & n. 10 & p. 17-30 & dez. 2014 \\
\hline
\end{tabular}

